\title{
SELECTION OF STRAINS OF Beauveria bassiana AND Metarhizium anisopliae (ASCOMYCOTA: HYPOCREALES) FOR ENDOPHYTIC COLONIZATION IN COCONUT SEEDLINGS
}

\author{
Jackeline Gaviria ${ }^{1 *}$, Pedro Pablo Parra ${ }^{2}$, Alonso Gonzales ${ }^{3}$ \\ ${ }^{1}$ Corporación Colombiana de Investigación Agropecuaria (AGROSAVIA), Diagonal a la intersección de \\ la Carrera 36A con Calle 23, Palmira, Colombia. \\ ${ }^{2}$ Tropical Research \& Education Center, University of Florida, Homestead, FL 33031-3314, USA. \\ ${ }^{3}$ AGO Consulting, Cali, Colombia. \\ * Corresponding author E-mail: jgaviria@agrosavia.co
}

\begin{abstract}
Beauveria bassiana and Metarhizium anisopliae are considered virulent pathogens of the coconut weevil Rhynchophorus palmarum (Linnaeus). The objective of this study was to determine the ability of B. bassiana (Beauveriplant SBb36) and M. anisopliae (JGVM1) to establish an endophytic relationship with coconut Cocos nucifera (Linnaeus) seedlings. Strains were selected based on the mortality of adults of R. palmarum exposed to these fungi. Three methods of inoculation were used to inoculate the seedlings obtained through seed germination: foliar spray, stem injection and drench to the roots. Immersion of seedlings in a conidial suspension was used to inoculate seedlings obtained from tissue culture. Colonization was determined through the re-isolation of the fungi four weeks after inoculation. Beauveriplant SBb36 and JGVM1 colonized endophytically $100 \%$ of the seedlings obtained through tissue culture and $91.6 \%$ of seedlings obtained from germinated seeds. For plants inoculated by immersion with B. bassiana, the colonization rate in petioles (43\%) was higher than in leaves and roots, 14 and 17\%, respectively. Metarhizium anisopliae did not show significant differences in the colonization rate in leaves, petioles and roots. Plants inoculated by foliar spraying showed that colonization was higher in leaves $>$ petioles $>$ stems $>$ roots. Colonization in stem injection was higher in stems than in the roots. Soil drench inoculation was higher in roots $>$ stems. To our knowledge, this is the first report describing the endophytic relationship that $B$. bassiana and M. anisopliae establish with coconut seedlings obtained through seed germination and tissue culture when targeted inoculations are performed.
\end{abstract}

Key words: Biological control, entomopathogens, endophyte, coconut palm, seeds, tissue culture.

\section{RESUMEN}

Beauveria bassiana y Metarhizium anisopliae son considerados patógenos virulentos contra el picudo Rhynchophorus palmarum. El objetivo de este estudio fue determinar la habilidad de la cepa comercial Beauveriplant SBb36 de B. bassiana y la cepa JGVM1 de M. anisopliae, para establecer una relación endofítica con plantas de coco Cocos nucifera (Linnaeus) obtenidas a partir de semilla sexual y de cultivo de tejidos. Se evaluaron diferentes métodos de inoculación: aspersión foliar, inyección en tallo y aplicación de suspensión conidial en las raíces, fueron usados para inocular plantas obtenidas a partir de semilla sexual, mientras que el método de inmersión fue usado para inocular plantas obtenidas a partir de cultivo de tejidos. El porcentaje de colonización en diferentes tejidos de las plantas se determinó a través del re-aislamiento de los hongos cuatro semanas después de la inoculación. Las cepas Beauveria bassiana (Beauveriplant SBb36) y Metarhizium anisopliae (JGVM1) colonizaron endofíticamente el $\mathbf{1 0 0} \%$ de las plantas de coco obtenidas a partir de cultivo 
de tejidos y el $\mathbf{9 1 . 6 \%}$ de las plantas de coco obtenidas por semilla sexual. En el presente estudio, se reporta por primera vez que $B$. bassiana and M. anisopliae establecen una relación de endofitismo con plántulas de coco obtenidas a partir de la germinación de semilla sexual y cultivo de tejidos a través de inoculaciones dirigidas.

Palabras clave: Control biológico, entomopatógenos, endófitos, palma de coco, semillas, cultivo de tejidos.

\section{INTRODUCTION}

The coconut palm Cocos nucifera (Linnaeus) (Arecaceae) is an industrial crop from which several and highly valuated products with important nutritional composition (Manivannan et al., 2018), such as oil, milk, cream, fibers, activated carbon, and coconut water, are obtained. It is also an important source of food and income for small-scale farmers around the world. In Colombia, coconut is especially important for low-income Afro-Colombian communities along the Pacific coast. It is grown under very special conditions (influenced by the tide) where no other agricultural crop is able to grow, becoming almost the only alternative for these communities. Despite its importance, the coconut production in the Pacific region has decreased dramatically due to the American palm weevil (APW) Rhynchophorus palmarum (Linnaeus). This insect is the most important coconut pest in many countries of Latin America and the Caribbean (Löhr et al., 2015). The APW attacks not only coconut palms but also a large number of cultivated and wild palms.

In Colombia R. palmarum is widely distributed along different coconut and oil palm growing zones (Aldana et al., 2011). It is the main vector of Bursaphelenchus cocophilus (Cobb) (Aldana et al., 2011), the nematode associated with the red ring disease (RRD), which is lethal to coconut and other palm species. In addition, APW larval stages cause direct damage to palms by feeding at the base of petioles, inflorescences and stem. The larval feeding causes palm weakening and sometimes palms die because of severe larval damage on meristematic tissue (Oehlschlager et al., 2002; Lohr et al., 2015).

Management strategies against the APW have shown limited success, mainly because this insect develops most of its life cycle inside the plant tissues (Aldana et al., 2011). This behavior makes detection and eradication difficult to achieve. Cultural practices such as mass trapping (Oehlschlager et al., 2002) and eradication of Red Ring Diseased palms (Aldana et al., 2011) are currently the most commonly used management strategies in Colombia. However, these practices are costly and labor intensive. The use of chemical pesticides for the APW management is highly impractical because of the height of palms (Aldana et al., 2011), development of resistance against pesticides, environmental pollution and high costs to farmers. An alternative to reduce the damage caused by larval feeding and transmission of the nematode is the biological control of larval and adult stages of the insect by using entomopathogenic fungus like B. bassiana (Bals.) Vuill and M. anisopliae (Metsch) Sorokin (Ascomycota: Hypocreales). Despite entomopathogenic fungi are used as biopesticides, this alternative requires recurrent applications and their efficacy depend on environmental conditions, such as temperature, humidity, radiation, among other factors (O'Callaghan et al., 2001). Other biocontrol alternatives that do not have these restrictions are ideal in plantations that require labor-intensive management practices, such as mass trapping and pesticide applications.

The use of entomopathogenic fungi as endophytes may play an important role in plant protection against pest and diseases (Jaber and Ownley, 2017). They could be the most suitable alternative to combat larval stages found inside plants (Azevedo et al., 2000). Fungal species like B. bassiana and M. anisopliae are often used in the biological control of pests in agricultural crops (Vega et al., 2008; Jaronski, 2010).

The fungus $B$. bassiana is the best studied endophytic fungal entomopathogen (Ownley et al., 2008; Jaber, 2015; Vidal and Jaber, 2015; Greenfield et al., 2016). This fungus has been inoculated in corn (Zea mays) to control Ostrinia nubilalis (Hübner) (Wagner and Lewis, 2000), in date palm to control red date scale Phoenicococcus marlatti (Cockerell) (Gómez-Vidal et al., 2006), in coffee to control the coffee berry borer Hypothenemus hampei (Ferrari) (Posada et al., 2007), and in cocoa to control the cocoa pod borer Conopomorpha cramerella (Snellen) (Posada and Vega, 2005). In adittion, B. bassiana has been inoculated in banana to control the banana weevil Cosmopolites sordidus (Germar), showing a damage reduction of $50 \%$ caused during immature stages of banana plants (Musa spp.) obtained from tissue culture (Akello, 2008).

Another fungus used as endophyte is $M$. anisopliae; this fungus has the ability to colonize rhizomes and roots of plants, such as cabbage 
(Brassica oleracea), fir (Abies), tomato (Solanum lycopersicum), corn (Zea mays) (Hu and Leger, 2002; Bruck, 2005; Garcia et al., 2011), broad bean (Aphis fabae) (Akello and Sikora, 2012), and cassava (Manihot esculenta) (Greenfield et al., 2016). When M. anisopliae was found in corn as an endophyte, it promoted plant development, increased seed germination rate and protected the plant against Coleopteran pests (Kabaluk et al., 2007; Garcia et al., 2011). It has been also shown that this species reduces the larval damage of Plutella xylostella (Linnaeus) in Brassica napus plants (Batta, 2013).

Based on previous evidence of the beneficial effects of these two fungal species and their use as biological control agents, the objective of this study was to assess the ability of B. bassiana and $M$. anisopliae to establish as endophyte in coconut seedlings using different inoculation methods.

\section{MATERIALS AND METHODS}

\section{The experiments}

Three experiments were conducted at the International Center for Tropical Agriculture (CIAT) in Palmira $\left(3^{\circ} 30^{\prime} 17^{\prime \prime} \mathrm{N}\right.$; 76 $\left.21^{\prime} 24^{\prime \prime} \mathrm{O}\right)$, Colombia. For all experiments, the inoculum consisted of a conidial suspension adjusted to $1 \times 10^{8}$ conidia $\mathrm{mL}^{-1}$. In the first experiment, the most pathogenic strain of $B$. bassiana and $M$. anisopliae was selected based on the $R$. palmarum adults' mortality when they were exposed to the entomopathogenic fungi. A completely randomized design with six treatments, four replications, and 20 experimental units per treatment was used. The experiment was repeated twice. The second and third experiments consisted of plants inoculated with the most pathogenic strain of B. bassiana, and M. anisopliae. In both experiments, the control consisted of plants treated with a sterile solution $0.1 \%$ Tween 80.

Seedlings derived from tissue culture were inoculated by immersion; a completely randomized design with five replications was used. Seedlings obtained from coconut seeds were inoculated using three inoculation methods (foliar spraying, stem injection and soil drench). A complete randomized block design with four replications was used.

\section{Entomopathogenic fungi}

Two isolates of $B$. bassiana (Beauveriplant strain SBb36 and Mycotrol strain GHA produced by Sanoplant $\AA$ and Laverlam S.A, respectively) and two isolates of M. anisopliae (Metarhiplant and Metatropico strain 9236 produced by Sanoplant ${ }^{\circledR}$ and Tropic microbial solutions, Cenicafé, respectively) were obtained from commercial sources and reactivated on adults of R. palmarum (Akello et al., 2009). The reactivation was carried by diluting commercial strains in a $0.1 \%$ Tween- 80 solution to obtain a concentration of $1 \times 10^{8}$ conidia $\mathrm{mL}^{-1}$. Five adult females of $R$. palmarum were immersed into the suspension for five minutes and then placed individually inside a $90 \mathrm{~mm}$ sterile Petri plate with sterile moist filter paper at the base for two weeks. The Petri plates were inspected on daily basis, and insects showing mycosis were removed to re-isolate the fungus.

A third isolate of $M$. anisopliae (JGVM1) was obtained directly from adults of $R$. palmarum collected in the main coconut growing area on the Colombian Pacific coast $\left(01^{\circ} 48^{\prime} 24^{\prime \prime} \mathrm{N}\right.$; $78^{\circ} 45^{\prime} 53^{\prime \prime} \mathrm{O}$, Tumaco, Nariño). A total of 150 adult weevils were captured using pheromone-baited traps, properly packed and taken to the laboratory. Isolation was performed following the method proposed by Goettel and Inglis (1997): dead insects were sprayed superficially with alcohol $70 \%$ for 20 seconds, 5\% sodium hypochlorite for two minutes and three final washings with sterile distilled water. Thereafter, insects were placed in individual humid chambers at $25 \pm 3^{\circ} \mathrm{C}$ in complete darkness during 20 days or until the fungus sporulated. Insects showing mycosis were removed from the humid chamber. The spores were collected by scraping the surface with a sterile needle. Fungal identification was based on morphological features, following the taxonomic keys proposed by Barnett and Hunter (1998) and Humber (1997).

Monosporic cultures of each strain (commercial and native) were prepared according to the protocol developed by Alvarez et al. (2005), and used as a source of inoculum for all experiments. Spores from the pure sporulated culture were taken and placed into $1 \mathrm{~mL}$ of a $0.1 \%$ water solution of Tween-80 and vortexed for 10 seconds. Then, $100 \mu \mathrm{L}$ of spore suspension was plated on 3\% Noble agar (Sigma Aldrich, San Luis, Missouri, USA) and incubated for $24 \mathrm{hr}$ at $25 \pm 3^{\circ} \mathrm{C}$ in the dark. A single germinated spore was picked and transferred to yeast malt agar medium (YMA, Sigma Aldrich), containing $2 \mathrm{mg}$ $\mathrm{L}^{-1}$ of tetracycline, $2 \mathrm{mg} \mathrm{L}^{-1}$ streptomycin and $2 \mathrm{mg}$ $\mathrm{L}^{-1}$ penicillin (Posada et al., 2007). The culture was allowed to grow during four weeks at $25 \pm 3^{\circ} \mathrm{C}$ and L12:D12 photoperiod. Monosporic cultures were used as source of fungi for all tests on insects and plant material.

\section{Inoculum preparation}

Sporulated monosporic cultures of each strain were prepared individually on laminar flow chamber. Conidia were removed from 
the surface of the medium and suspended in $10 \mathrm{~mL}$ of $0.1 \%$ Tween- 80 and vortexed for one minute. Excess of mycelium was removed by filtering the solution through sterile cheesecloth. Serial dilutions from $10^{-1}$ to $10^{-4}$ were prepared to facilitate spore counting using a Neubauer chamber (ThermoFísher Scientific, Colombia). The solution was adjusted to a final concentration of $1 \times 10^{8}$ conidia $\mathrm{mL}^{-1}$.

Purity and viability was estimated for each strain. The purity test was conducted by plating $100 \mu \mathrm{L}$ of the $10^{-4}$ spore dilution on YMA medium and incubated for seven days at $25 \pm 3^{\circ} \mathrm{C}$ in complete darkness. Purity was determined by counting the number of colony forming units (CFU) of the entomopathogenic fungi in relation to the total number of CFU present in the Petri dish (Marín and Bustillo, 2002). A viability test was conducted by plating $5 \mu \mathrm{L}$ aliquots $\left(10^{-3}\right.$ dilution) in five points of a Petri dish containing $1.5 \%$ noble agar and incubated at $25 \pm 3^{\circ} \mathrm{C}$ in complete darkness for 24 hours. After 24 hours a drop of lactophenol blue was added to stop germination. Germinated spores were counted by randomly selecting 3 groups of 100 conidia. Results were expressed as percentage (Marín and Bustillo, 2002).

\section{Isolates selection}

The most pathogenic isolates of $B$. bassiana and $M$. anisopliae were selected based on the mortality of adults of $R$. palmarum. The weevils were collected using pheromone-baited traps in sugarcane fields; insects were $3.5-4 \mathrm{~cm}$ in length and weighed 1.5-2.0 g. After capture, insects were quarantined in laboratory for 15 days. Prior to inoculation, insects were individually washed with tap water and surface disinfested with sodium hypochlorite $0.5 \%$ for two minutes, followed by three washings with sterile distilled water. The experiment was conducted using a completely randomized design, with six treatments and four replications, including a control treatment (Table 1). Twenty experimental units per treatment were used.

To ensure contact of weevils with entomopathogenic fungi, each insect was immersed during two minutes in a $50 \mathrm{~mL}$ suspension containing $1 \times 10^{8}$ conidia $\mathrm{mL}^{-1}$. This procedure was performed for each fungal strain of both species. Controls consisted of immersion of weevils in a solution of $0.1 \%$ Tween- 80 for two minutes. Each insect was individually transferred to translucent plastic boxes $(120 \times 100 \times 70$ mm, Darnel, Selloplus ${ }^{\circledR}$, Ajover S.A., Bogota, Colombia), with an opening covered with a sterile mesh in the lid to facilitate aeration. Each box contained $10 \mathrm{~g}$ of wet sugar cane sawdust and $5 \mathrm{~cm}$ piece of sugar cane previously autoclaved for $20 \mathrm{~min}$ at $120^{\circ} \mathrm{C}$ and 20 psi. Plastic boxes were maintained in the incubator at $28 \pm 2^{\circ} \mathrm{C}$ and L12:D12 photoperiod for three weeks. Plastic boxes were evaluated every 24 hours. Dead insects were counted and removed from boxes and transferred to humid chambers to facilitate fungal sporulation. The sawdust and sugar cane pieces were replaced on weekly basis.

\section{Inoculation of coconut seedlings obtained from tissue culture}

Coconuts seedlings were obtained in the laboratory by using a zygotic embryos rescue procedure according to Rillo (2004). Three months old seedlings with three true leaves were transferred individually to $50 \mathrm{~mL}$ of liquid medium Y3 (Eeuwens, 1976). Seedlings were covered with plastic bags to facilitate acclimation and root development. Afterwards, plants were maintained under laboratory conditions at 27 $\pm 2^{\circ} \mathrm{C}$ with a photoperiod L12: D12 during four additional weeks.

Five month-old plants were removed from the medium and washed with tap water for five minutes. Each plant was inoculated separately by

Table 1. Beauveria bassiana and Metarhizium anisopliae strains evaluated for pathogenicity and their source.

\begin{tabular}{|c|c|c|c|}
\hline Strain & Fungi & Source & Company \\
\hline SBb36 & Beauveria bassiana & Beauveriplant & Sanoplant ${ }^{\circledR}$ \\
\hline \multirow[t]{2}{*}{ GHA } & Beauveria bassiana & Mycotrol & Laverlam S.A \\
\hline & Metarhizium anisopliae & Metarhiplant & Sanoplant ${ }^{\circledR}$ \\
\hline 9236 & Metarhizium anisopliae & Metatropico & $\begin{array}{l}\text { Soluciones microbianas de } \\
\text { trópico (Cenicafé) }\end{array}$ \\
\hline JGVM1 & Metarhizium anisopliae & $\begin{array}{l}\text { Field collection of } \\
\text { Rhynchophrous } \\
\text { palmarum from Tumaco, } \\
\text { Colombia }\end{array}$ & \\
\hline
\end{tabular}


immersion during one hour in $600 \mathrm{~mL}$ of a conidial suspension of B. bassiana and M. anisopliae strains selected. Seedlings in the control treatment were immersed during one hour in a sterile solution of $600 \mathrm{~mL}$ of $0.1 \%$ Tween-80. After inoculation, plants were transferred individually to 3000 $\mathrm{mL}$ plastic bags containing sterile substrate and maintained under greenhouse conditions $\left(22-30^{\circ} \mathrm{C}\right.$ with natural light). After four weeks, seedlings were tested for the presence of the two inoculated entomopathogenic species.

\section{Inoculation of coconut seedlings obtained from coconut seeds}

Five-month-old seedlings were obtained from a "hybrid" population of palms from the Pacific Coast (Tumaco) in Colombia. Before plants were introduced to the greenhouse for sowing, coconuts were treated with low doses of the fungicide tebuconazole (Folicur $(\circledR)$ ) and the insecticide Malathion, as a phytosanitary measure. After treatment, germinating seeds were transplanted into $10 \mathrm{~kg}$ pots with sterile substrate and maintained under greenhouse conditions (22-30 ${ }^{\circ} \mathrm{C}$ with natural light) for six months before inoculation. Seedlings were irrigated every 48 hours and fertilization was applied as required. Twelve-month-old seedlings were inoculated with conidial suspensions of $B$. bassiana and $M$. anisopliae selected, by the following methods 1 ) foliar spray, 2) stem injection, and 3) soil drench (Posada et al., 2007).

For foliar spray application, $10 \mathrm{~mL}$ conidial suspension ( $1 \times 10^{8}$ conidia $\left.\mathrm{mL}^{-1}\right)$ was applied directly to leaves with a hand-held spray bottle. Each pot was covered with alumina foil during inoculation to prevent conidial suspension runoff to the soil. Each inoculated plant was covered with a sterile plastic bag for 24 hours to maintain a high humidity level and facilitate fungal growth. Control treatment consisted of seedlings sprayed with a $0.1 \%$ Tween- 80 sterile solution.

In the stem injection method, seedlings were injected at the base of the stem with $30 \mu \mathrm{L}$ of a conidial suspension $\left(1 \times 10^{8}\right.$ conidia $\left.\mathrm{mL}^{-1}\right)$ or $0.1 \%$ Tween- 80 (control) using a Hamilton syringe (Hamilton $®$, Nevada, USA). To facilitate inoculation, a tiny hole was previously made with a $21 \mathrm{G}$ sterile disposable hypodermic needle (RYMCOC, Barranquilla, Colombia). After inoculation, the wound was covered with waxed film (Parafilm, Bemis NA, Neenah, Wisconsin) to prevent contamination with external microorganims.

For the soil drench method, plants were inoculated by drenching $10 \mathrm{~mL}$ of a conidial suspension $\left(1 \times 10^{8}\right.$ conidia $\left.\mathrm{mL}^{-1}\right)$ around the root area. Control seedlings received $10 \mathrm{~mL}$ solution of $0.1 \%$ Tween- 80 solution as described above.

After inoculation, all plants were maintained under greenhouse conditions for four weeks. A complete randomized block design with four replicates per treatment was used.

\section{Detection of M. anisopliae and B. bassiana as endophytes}

Four weeks after inoculation, both tissue cultured seedlings and seedlings from seeds were removed from the substrate and rinsed thoroughly with tap water to remove excess substrate. From each plant, two random leaves were taken ( 3 segments per leaf: proximal, distal and basal), two tissue sections collected from the base and the middle of the stem, two petiole sections, and three sections of roots were surface sterilized in a laminar flow chamber with $0.5 \%$ solution of sodium hypochlorite for two minutes, $70 \%$ ethanol for two minutes and then rinsed three times with sterile distilled water (Posada et al., 2007). An aliquot of the last rinse was spread on YMA medium to determine the success in removal of epiphytic microorganisms. Ten segments from each portion of leaf, petiole, stem and roots (2-4 mm long) were put in $90 \mathrm{~mm}$ Petri dishes containing YMA medium supplemented with 2 $\mathrm{mg} \mathrm{L}^{-1}$ of tetracycline, $2 \mathrm{mg} \mathrm{L}^{-1}$ of streptomycin and $2 \mathrm{mg} \mathrm{L}^{-1}$ of penicillin. The petri plates were incubated at $25 \pm 3^{\circ} \mathrm{C}$ for three weeks and each fragment was visually examined on a daily basis. Growth of entomopathogenic fungi and other contaminants were recorded to establish colonization rates. For each sampled tissue, the colonization rate was calculated according to the number of segments colonized by M. anisopliae or B. bassiana in relation to the total number of plated segments. Seedlings obtained from tissue culture did not have a well-developed stem this should be a comma rather than a period therefore, only leaves, petioles and roots were evaluated.

\section{Statistical analysis \\ Isolates selection}

The block effect was determined by using a proportions homogeneity test. To select the most pathogenic isolates, data corresponding to mortality were analyzed using an analysis of variance (ANOVA). Prior to analysis, mortality rates were mathematically transformed (arcsine). Normality of the transformed data and variance homogeneity were tested and confirmed. Significant differences found between treatments were separated using the Tukey test $(\mathrm{p}<0.05)$. Lethality time of LT50 and LT80 were estimated by a simple regression analysis. The cumulative mortality was compared with the time elapsed since the inoculation time. 


\section{Inoculation of coconut seedlings}

Colonization rates of each fungal strain with the different inoculation methods were analyzed using a logistic regression. The colonization rate of plant organs obtained from sexual seeds was analyzed using a proportion of homogeneity test ( $R$ version 3.0.0., 2013)

\section{RESULTS AND DISCUSSION}

After the reactivation of strains of B. bassiana and $M$. anisopliae using adult females of $R$. palmarum, the conidial viability of the five isolates was as follows: 95.4\% (JGVM1); 90.6\% (Metarhiplant); 89.3\% (Beauveriplant strain SBb36); $78.3 \%$ (Mycotrol GHA) and 92.5\% (Metatropico strain 9236). Purity was above $98 \%$ for all strains.

\section{Isolates selection}

Isolates from the two entomopathogenic fungi used in this study showed significant differences in weevil mortality 15,18 and 19 days after inoculation (day 15: $\mathrm{F}=5.707, \mathrm{df}=4, \mathrm{P}=0.005 ;$ day $18: \mathrm{F}=5.604$ , $\mathrm{df}=4, \mathrm{P}=0.005$ and day $19: \mathrm{F}=3.385, \mathrm{df}=4, \mathrm{P}=$ 0.036 ). The highest mortality for B. bassiana and M. anisopliae was reached at 19 and 17 days after inoculation with strains Beauveriplant SBb36 and JGVM, respectively (Fig. 1). Gindin et al. (2006) reported up to $100 \%$ mortality of Rhynchophorus ferrugineus (Olivier) larvae and adults two and five weeks after inoculation for strains of $M$. anisopliae and B. bassiana. In other studies, Shawir and Al-Jabr (2010) evaluated the pathogenicity of two strains of B. bassiana and M. anisopliae on $R$. ferrugineus. A mortality rate of $80 \%$ was observed 10 days after inoculation on larvae, while a $85 \%$ was observed 15 days after inoculation on adults treated with B. bassiana. Meanwhile, larvae and adults of $R$. ferrugineus treated with $M$. anisopliae showed between 60\% to100\% mortality (Shawir and Al-Jabr, 2010).

Out of all tested isolates, Metarhizium anisopliae strain JGVM1 showed the greatest mortality in the shortest time, reaching $100 \%$ mortality 17 days after inoculation. Commercial strains Metarhiplant and Metatropico 9236, showed 80 and $85 \%$ of mortality respectively 17 days after inoculation, and were significantly different from strain JGVM1 but did not showed significant differences among each other (Tukey $=0.9794)$.

Lethality times LT50 and LT80 of strain JGVM1 $($ LT50 $=11.3$ days; LT80 $=16.2$ days $)$ were lower than those observed for strains Metatropico $9236($ LT50 $=14.1$ days; LT80 $=20.3$ days $)$ and Metarhiplant $($ LT50 $=13.7$ days; LT80 $=19.6$ days). The mean time of lethality obtained for JVM1 strain was lower than the LT50 of 13.1 days reported by Francardi et al. (2012) in adults of $R$. ferrugineus infected with native strains of $M$. anisopliae isolated directly from weevils.

Similarly, the LT50 for Beauveriplant SBb36 was 12.2 days, while Francardi et al. (2012) reported 15 days for $B$. bassiana on adults of $R$. ferrugineus. Entomopathogenic fungi do not produce acute mortality on their insect host, instead, these microorganisms act gradually by reducing activity, feeding rate (Tefera and Pringle, 2003), reproductive potential of the insect (Gindin et

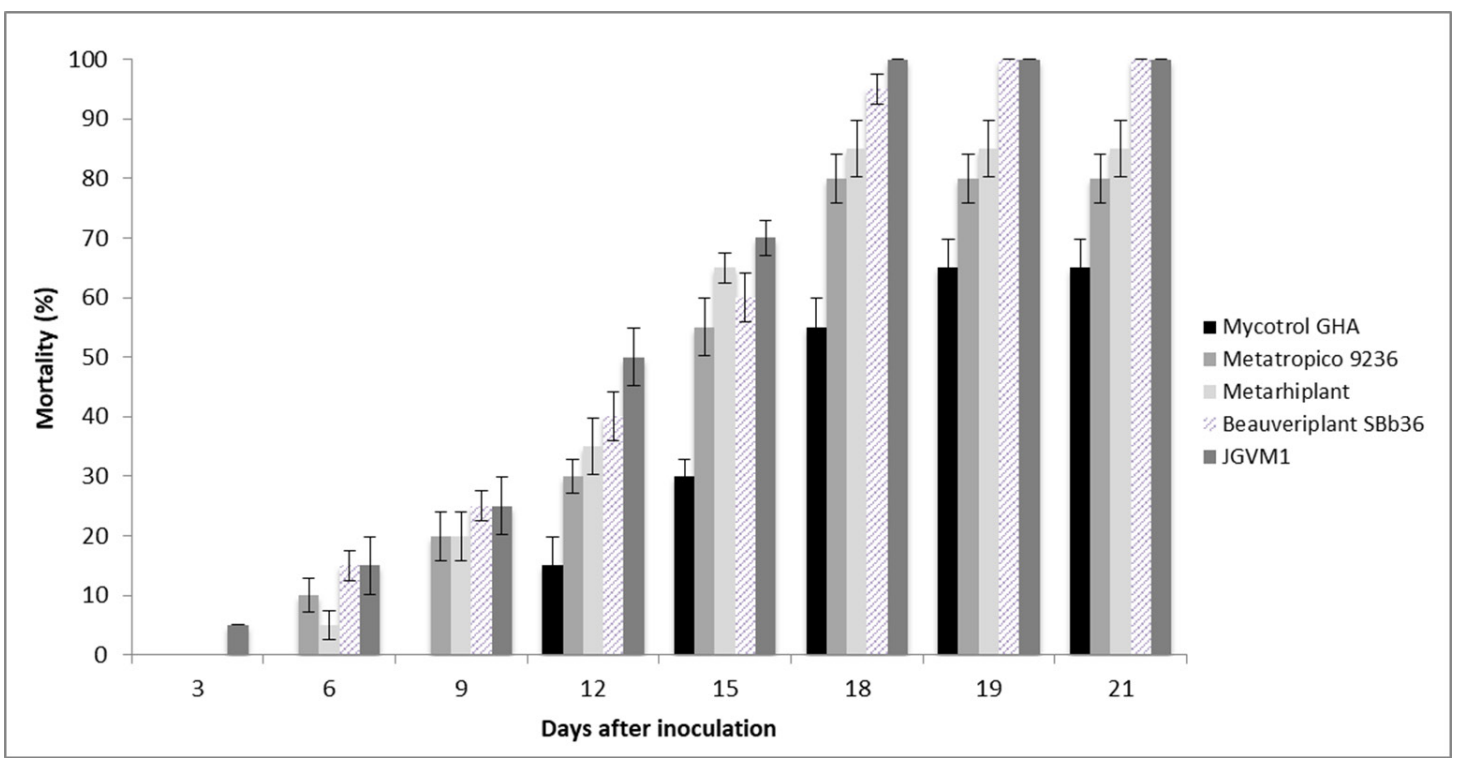

Fig. 1. Cumulative mortality of Rhynchophorus palmarum adults after inoculation with Beauveria bassiana (Mycotrol GHA, Beauveriplant SBb36) and Metarhizium anisopliae (Metatropico 9236, Metarhiplant, JGVM1). 
al., 2006; Kaur et al., 2011) and finally death. Several authors suggest that the sources of food contaminated with entomopathogenic fungi like B. bassiana or M. anisopliae might repel the larvae and therefore reduce the feeding rate, as in the grasshopper Stiphra robusta, when exposed to leaves sprayed with Metarhizium anisopliae (Magalhães et al., 2001).

BeauveriplantSBb36 presented higher mortality than Mycotrol GHA during the evaluation period $($ Tukey $=0.006)$, reaching $100 \%$ mortality 19 days after inoculation, while the highest mortality recorded for Mycotrol reached 65\% after 21 days of inoculation. The time elapsed to kill $50 \%$ and $80 \%$ of the population (LT50 and LT80) was 12.2 and 17.4 respectively for Beauveriplant SBb36; this values were significantly lower than those obtained for Mycotrol GHA (LT50 $=18.2$ and LT80 $=27.1$ days).

\section{Inoculation of plants}

The experiments in which entomopathogenic fungi were inoculated on coconut plants were carried out using the most highly virulent strains on adult weevil. For B. bassiana strain, Beauveriplant SBb36 and M. anisopliae strain JGVM1 were selected.

\section{Inoculation of coconut seedlings obtained from tissue culture}

Both entomopathogens were recovered from all inoculated seedlings derived from tissue culture. Similar results were found by Akello et al.
(2007) with $95 \%$ of colonization found in in vitro plants of Musa spp. inoculated with B. bassiana. No entomopathogenic fungi were found in seedlings inoculated with $0.1 \%$ Tween- 80 (control treatment).

Of the 600 tissue fragments obtained from inoculated plants, 146 fragments $(24.3 \%)$ were colonized by B. bassiana and M. anisopliae, 78 fragments $(13 \%)$ presented colonization by endophytic bacteria and 46 fragments (7.7\%) were colonized by other fungi. The 330 remaining fragments showed no growth of microorganisms. The colonization rate of $B$. bassiana significantly varied between plant parts $\left(\chi^{2}=27.37, \mathrm{df}=2\right.$, $\mathrm{P}=0.000001)$. The colonization rate in petiole fragments $(43 \%)$ was significantly higher than that recorded in leaves and roots (14 and 17\%, respectively) (Fig. 2). The greater colonization in petioles can be due to differences in physiological and microbiological conditions within the parts of the plant. Many endophytic fungi show specificity to different parts of the plant because they are adapted to particular conditions present in tissues (Akello et al., 2007). Metarhizium anisopliae did not show significant differences between colonization rates in leaves, petioles and roots $(20,23$ and $29 \%$, respectively) $\left(\chi^{2}=1.4254, \mathrm{df}=2, \mathrm{P}=0.4903\right)$.

The colonization rate in petioles was significantly higher in plants inoculated with Bauveriplant SBb36 (43\%) than in those inoculated with JGVM1 $(23 \%)(\mathrm{z}=2,971, \mathrm{df}=1, \mathrm{P}=0.0029)$. No differences were observed between colonization rates in roots $(\mathrm{z}=1,847, \mathrm{df}=1, \mathrm{P}=0,064)$ and leaves $(\mathrm{z}=1,295, \mathrm{df}=1, \mathrm{P}=0,195)$.

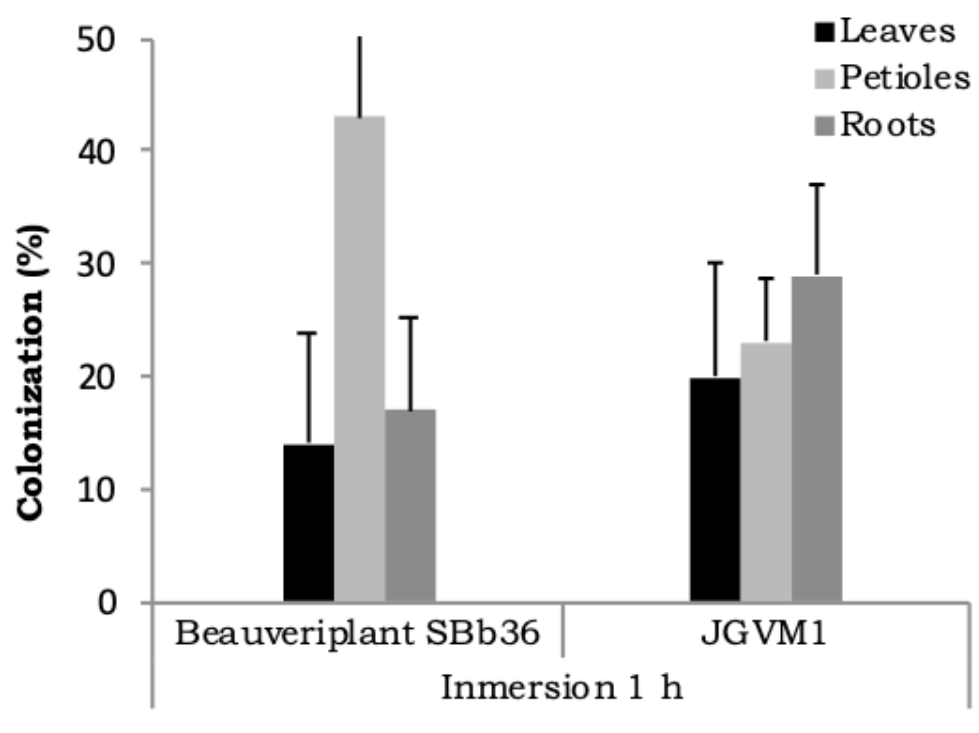

Fig. 2. Colonization rate of coconut plantlets obtained from tissue culture and inoculated by immersion with Beauveria bassiana, (Beauveriplant SBb36) and Metarhizium anisopliae, (strain JGVM1). 
Inoculation of seedlings germinated from coconut seeds

All three-inoculation methods used were effective for endophytic colonization of the fungi B. bassiana and M. anisopliae. Both species were recovered from $91.6 \%$ of inoculated plants. However, there is an interaction between the plant tissue colonized and the method of inoculation used. Similar results were found by Russo et al. (2015), who found significant differences in colonization when several inoculation techniques were used in different plant organs. Colonization by foliar spraying was higher in leaves, than in petioles, stems, and roots. Colonization by stem injection was higher in stems than roots. Soil drench inoculation showed higher colonization in roots than stems. These results show that the endophytic colonization in different parts of the plant depends on the inoculation method (Fig. 3). In coffee, the highest post-inoculation recovery of B. bassiana occurred by direct injection of plants (Posada et al., 2007); in banana tissue cultured plants, higher colonization was obtained by dipping plants in a conidial suspension (Akello et al., 2007). On the other hand, in Opium poppy (Quesada-Moraga et al., 2006) and corn (Cherry et al., 2004) higher colonization was obtained by foliar application; and in tomato by seed coating (Ownley et al., 2008). Drench inoculation in coffee (Coffea arabica) plants and common bean (Phaseolus vulgaris) promoted the colonization of roots, while foliar sprays promoted the colonization mainly of leaves (Posada et al., 2007, Parsa et al., 2013). In this way, the inoculation method chosen to control a pest should be directed to the place where the insect attacks inside the plant (Parsa et al., 2013). For R. palmarum, which mainly attacks the crown, inflorescences, petioles and stems, inoculations should be directed to these organs using the most suitable method. In this sense, the results of our study indicated that the most effective method is stem injection. Similar results were reported by Sewify et al. (2009), who used this method to inoculate a native strain of $B$. bassiana isolated from a $R$. ferrugineus cadaver in naturally infested palm trees, reducing the incidence of $R$. ferrugineus by 90\% under field conditions in Egypt.

None of the plants in the control treatment showed fungal growth of any entomopathogenic fungi.

Regardless of the plant tissue evaluated, from a total of 1920 tissue fragments from inoculated plants, $11 \%$ were colonized by $M$. anisopliae (JGVM1), and $4.9 \%$ were colonized by B. bassiana (Beauveriplant SBb36), while 14\% showed growth of endophytic bacteria and $4.3 \%$ showed growth of other fungi.

Strain JGVM1 of M. anisopliae inoculated by foliar spray was recovered from leaves $(21.5 \%)$, petioles $(26.3 \%)$ and stems $(12.5 \%)$, while strain Beauveriplant SBb36 was recovered from leaves $(12.5 \%)$, petioles $(10 \%)$ and stems $(1.25 \%)$. The

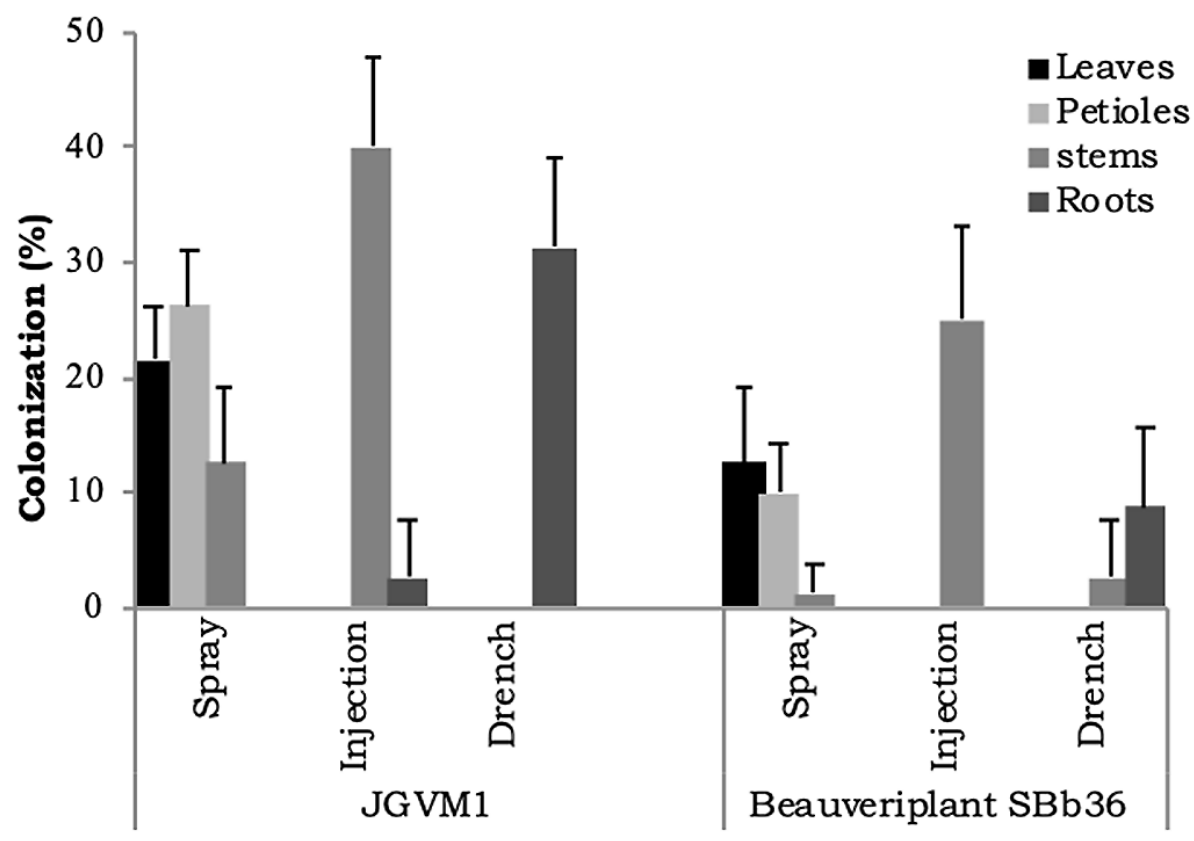

Fig. 3. Colonization rate of coconut seedlings inoculated with Beauveria bassiana (Beauveriplant SBB36) and Metarhizium anisopliae (strain JGVM1) with different methods (foliar spraying, stem injection and application in drench. 
method of direct injection with Beauveriplant SBb36 resulted only in stem colonization (25\%), whereas strain JGVM1 colonized stems (40\%) and roots $(2.5 \%)$.

Finally, soil drench produced colonization only in roots $(31.25 \%)$ for strain JGVM1, while Beauveriplant SBb36 colonized roots (8.75\%) and stems (2.5\%). These results indicate that B. bassiana and $M$. anisopliae can move through the plant. Similar results have been found in coffee plants inoculated with B. bassiana by stem injection, where the fungus was recovered from stems and roots (Posada et al., 2007). Inoculation by injection of the fungus B. bassiana and Lecanicillium c.f. psalliotae in petioles of date palm (Phoenix dactylifera) indicated that the fungi can be recovered $3 \mathrm{~cm}$ above and below the inoculation point (Gomez-Vidal et al., 2006). Bing and Lewis (1993) found that B. bassiana can be recovered from other sites different from the inoculation point in corn plants. Batta (2013), found the fungus $M$. anisopliae in leaves, petioles and stems after inoculation in leaves of Brassica napus. The movement of the entomopathogenic fungi within the plant may be attributed to either passive transport within the xylem or the growth of the mycelium. Wagner and Lewis (2000) successfully observed the growth of hyphae of B. bassiana in the xylem of corn plants after inoculating the fungus through foliar spray.

Significant differences were found between Beauveriplant SBb36 and M. anisopliae strain JGVM1 when plants were inoculated by injection $(\mathrm{z}=2.01, \mathrm{df}=1, \mathrm{P}=0.0443)$. Similar results were found after inoculation by drench $(\mathrm{z}=3.19, \mathrm{df}=$ $1, \mathrm{P}=0.0014)$. Both methods resulted in a higher colonization rate for strain JGVM1 (Fig. 3). No significant differences between the strains were observed when plants were inoculated by spraying $(\mathrm{z}=1,463, \mathrm{df}=1, \mathrm{P}=0,143)$.

The greater colonization of roots by Metarhizium anisopliae in both plants obtained from tissue culture and plants obtained from sexual seeds can be attributed to the specific association of this fungi with the rhizosphere of many plant species (Hu and St. Leger, 2002; Wyrebek et al., 2011). Hu and St. Leger (2002) reported that the rhizospheres of several plant species are potential reservoirs of Metarhizium spp.

\section{CONCLUSIONS}

This study shows that $B$. bassiana strain Beauveriplant SBb36 and M. anisopliae strain JGVM1 have the ability to colonize endophytically coconut seedlings from either tissue culture or coconut seed. The two entomopathogenic fungi were recovered from inoculated plant tissues. Nonetheless, further experiments need to be conducted to determine whether inoculated seedlings induce a reaction on Rynchophorus palmarum, either adults or larvae, before this method could be recommended as a practical alternative to reduce the damage caused by this weevil.

\section{ACKNOWLEDGEMENTS}

This research was funded by the program "Jovenes Investigadores e Innovadores Virginia Gutiérrez de Pineda" of Colciencias (Nro. 525 of 2012) and the International Center for Tropical Agriculture. Special thanks to Dr. Bernhard Löhr for his support and guidance. The authors also want to thank Alexander Medina for technical assistance in the development of this work. The information contained within this document was generated by the main author while working at the International Center for Tropical Agriculture CIAT, however, the author thanks the Colombian Agricultural Research Corporation AGROSAVIA.

\section{LITERATURE CITED}

Akello, J., T. Dubois, S.C. Gold, J. Nakavuma, and P. Paparu. 2007. Beauveria bassiana (Balsamo) Vuillemin as an endophyte in tissue culture banana (Musa spp.). Journal of Invertebrate Pathology 96:34-42.

Akello, J., T. Dubois, D. Coyne, and S. Kyamanywa. 2008. Endophytic Beauveria bassiana in banana (Musa spp.) reduces banana weevil (Cosmopolites sordidus) fitness and damage. Crop Protection 27:1437-1441.

Akello, J., T. Dubois, D. Coyne, and S. Kyamanywa. 2009. The effects of Beauvreria bassiana dose and exposure duration on colonization and growth of tissue cultured banana (Musa sp.) plants. Biological Control 49:6-10.

Akello, J., and R. Sikora. 2012. Systemic acropedal influence of endophyte seed treatment on Acyrthosiphon pisum and Aphis fabae offspring development and reproductive fitness. Biological Control 61: 215-221. https://doi. org/10.1016/j.biocontrol.2012.02.007

Aldana, R.C., J.A. Aldana, and O.M. Moya. 2011. Manejo del picudo Rhynchophorus palmarum Coleoptera: Curculionidae. Cenipalma, Bogotá, Colombia. 51 p.

Alvarez, E., C.A. Ospina, J.F. Mejía, y G. Ceballos 2005. Caracterización morfológica, patogénica y genética del agente causal de la antracnosis (Colletotrichum gloeosporiodies) en guanábana (Annona muricata) en el Valle del Cauca. Fitopatologia Colombiana 28(1):1-8. 
Azevedo, J.L., W.J. Maccheroni, J.O. Pereira, and W.L. Araújo. 2000. Endophytic microorganisms: a review on insect control and recent advances on tropical plants. Electronic Journal Biotechnology 3:40-65.

Barnett, H.L., and B.B. Hunter. 1998. Illustrated genera of imperfect fungi. 240 p. 3a. ed. American Phytopathological Society, Saint Paul, Minnesota, U.S.A

Batta, Y.A. 2013. Efficacy of endophytic and applied Metarhizium anisopliae (Metch.) Sorokin (Ascomycota: Hypocreales) against larvae of Plutella xylostella L. (Yponomeutidae: Lepidoptera) infesting Brassica napus plants. Crop Protection 44:128- 134.

Bing, L.A., and L.C. Lewis. 1993. Occurrence of the entomopathogen Beauveria bassiana (Balsamo) Vuillemin in different tillage regimes and in Zea mays L. and virulence towards Ostrinia nubilalis (Hübner). Agriculture, Ecosystems \& Environment 45:147-156.

Bruck, D.J. 2005. Ecology of Metarhizium anisopliae in soilless potting media and the rhizosphere: implications for pest management. Biological Control 32:155-163.

Cherry, A., A. Banito, D. Djegui, and C. Lomer.2004. Uppression of the stem-borer Sesamia calamistis (Lepidoptera; Noctuidae) in maize following seed dressing, topical application and stem injection with African isolates of Beauveria bassiana. International Journal of Pest Management 50:67-73.

Eeuwens, C.J. 1976. Mineral requirements for growth and callus initiation of tissue explants excised from mature coconut palms (Cocos nucifera) and cultured in vitro. Physiologia Plantarum 36:23-28.

Francardi, V.,C.Benvenuti,P.F.Roversi,P.Rumine, and G. Barzanti. 2012. Entomopathogenicity of Beauveria bassiana (Bals.) Vuill. and Metarhizium anisopliae (Metsch.) Sorokin isolated from different sources in the control of Rhynchophorus ferrugineus (Olivier) (Coleoptera Curculionidae). Redia 95:49-55.

Garcia, J.E., J.B. Posadas, A. Perticari, and R. Lecuona. 2011. Metarhizium anisopliae (Metschnikoff) Sorokin promotes growth and has endophytic activity in tomato plants. Advances in Biological Research 5(1):22-27.

Gindin, G., S. Levski, I. Glazer, and V. Soroker. 2006. Evaluation of the entomopathogenic fungi Metarhizium anisopliae and Beauveria bassiana against the red palm weevil Rhynchophorus ferrugineus. Phytoparasitica 34(4):370-379.
Goettel, M.S., and G.D. Inglis. 1997. Fungi: Hyphomycetes. Manual of Techniques in Insect Pathology. L.A. Lacey (ed.). p. 213-249. Academic Press, San Diego, USA.

Gómez-Vidal, S., L.V. Lopez-Llorca, H.B. Jansson, and J. Salinas. 2006. Endophytic colonization of date palm (Phoenix dactylifera L.) leaves by entomopathogenic fungi. Micron 37:624-632.

Greenfield, M., M. Gómez-jiménez, V. Ortiz, F.E. Vega, M. Kramer, and S. Parsa, 2016: Beauveria bassiana and Metarhizium anisopliae endophytically colonize cassava roots following soil drench inoculation. Biological Control 95:40-48.

Hu, G., and R. St. Leger. 2002. Field studies using a recombinant mycoinsecticide (Metarhizium anisopliae) reveal that it is rhizosphere competent. Applied and Environmental Microbiology 68(12):6383-6387.

Humber, R.A. 1997. Fungi: Identification. p. 153185. In L.A. Lacey (ed.) Manual of Techniques in Insect Pathology. Academic Press. New York, USA.

Jaber, L.R., and Ownley, B.H. 2017. Can we use entomopathogenic fungi as endophytes for dual biological control of insect pests and plant pathogens?. Biological Control 116. 10.1016/j.biocontrol.2017.01.018

Jaber, L.R. 2015. Grapevine leaf tissue colonization by the fungal entomopathogen Beauveria bassiana s.l. and its effect against downy mildew. BioControl 60:103-112.

Jaronski, S.T. 2010. Role of fungal ecology in the inundative use of entomopathogenic fungi. BioControl 55:159-185.

Kabaluk, J.T., M.S. Goettel, J.D. Ericsson, M.A, Erlandson, R.S. Vernon, S. Jaronski, et al.. 2007. Promise versus performance: Working toward the use of Metarhizium anisopliae as a biological control for wireworms. IOBCWPRS Bulletin 30:69-76.

Kaur, S., H.P. Kaur, K. Kaur, and A. Kaur. 2011. Effect of different concentrations of Beauveria bassiana on development and reproductive potential of Spodoptera litura (Fabricius). Journal of Biopesticides 4:161-168.

Löhr, B., A.A. Vásquez-Ordóñez, L.A. Becerra. 2015. Rhynchophorus palmarum in disguise: Undescribed polymorphism in the "Black" Palm Weevil. PLoS ONE 10(12): e0143210. https://doi.org/10.1371/journal.pone.0143210 Magalhães, B.P., M.R. De Faria, M. Lecoq, F.G. Schmidt, J.B. Silva, and H.S. Frazao. 2001. The use of Metarhizium anisopliae var. acridum against the grasshopper Rhammatocerus schistocercoides in Brazil. Journal Orthoptera Research 10:199-202. 
Manivannan, A., R. Bhardwaj, S. Padmanabhan, P. Suneja, K.B. Hebbar and S.R. Kanade. 2018. Biochemical and nutritional characterization of coconut (Cocos nucifera L.) haustorium. Food Chemistry 238:153-159.

Marín, P., y A.E. Bustillo. 2002. Producción artesanal de hongos entomopatógenos para el control de insectos plagas. p. 125-131. En Memorias Curso Internacional TeóricoPráctico. Sección I. Entomopatógenos de la broca del café. Cenicafé, Chinchiná., Colombia.

O'Callaghan, M., E.M, Gerard, and V.W. Johnson. 2001. Effect of soil moisture and temperature on survival and of microbial control agents. New Zealand Plant Protection 54:128-135.

Oehlschlager, C., C.M. Chinchilla, G. Castillo, and L. González. 2002. Control of red ring disease by mass trapping of Rhynchophorus palmarum (Coleoptera: Curculionidae). The Florida Entomologist 85(3):507-513.

Ownley, B.H., M.R. Griffin, W.E. Klingeman, K.D. Gwinn, K.J. Moulton, and R.M. Pereira. 2008. Beauveria bassiana: Endophytic colonization and plant disease control. Journal of Invertebrate Pathology 98:267-270.

Parsa, S., V. Ortiz, and F. Vega. 2013. Establishing fungal entomopathogens as endophytes: towards endophytic biological control. Journal of Visualized Experiments (74), e50360.

Posada, F., and F.E. Vega. 2005. Establishment of the fungal entomopathogen Beauveria bassiana (Ascomycota: Hypocreales) as an endophyte in cocoa seedlings (Theobroma cacao). Mycology 97:1195-1200.

Posada, F., M.C. Aime, S.W. Peterson, S.A. Rehner, and F.E. Vega. 2007. Inoculation of coffee plants with the fungal entomopathogen Beauveria bassiana (Ascomycota: Hypocreales). Mycological Research 111:748757.

Quesada-Moraga, E., B.B. Landa, J. MuñozLedesma, R.M. Jiménez-Diáz, and C. SantiagoAlvarez. 2006. Endophytic colonisation of opium poppy, Papaver somniferum, by an entomopathogenic Beauveria bassiana strain. Mycopathologia 161(5):323-329. doi: 10.1007/ s11046-006-0014-0

R Development Core Team. 2013. R: A language and environment for statistical computing. $\mathrm{R}$ Foundation for Statistical Computing, Vienna, Austria.
Rillo, E.P. 2004. Importing and growing embryos for the coconut genebank. In Germplasm Health Management for COGENTs [International Coconut Genetic Resources Network] multi-site international coconut genebank. Chapter 3. p. 60-67. IPGRI-APO, Malaysia.

Russo, M.L., S.A. Pelizza, M.N., Cabello, S.A. Stenglein and A.C. Scorsetti. 2015. Endophytic colonisation of tobacco, corn, wheat and soybeans by the fungal entomopathogen Beauveria bassiana (Ascomycota, Hypocreales). Biocontrol Science and Technology 25(4):475-480.

Shawir, M.S., and A.M. Al-Jabr. 2010. The infectivity of entomopathogenic fungi Beauveria bassiana and Metarhizium anisopliae to Rhynchophorus ferrugineus (Olivier) stages under laboratory conditions. Acta Horticulturae 882:431-436.

Sewify, G., B., Mohamed, and A., Al-Awash. 2009. Use of the entomopathogenic fungus, Beauveria bassiana for the biological control of the Red Palm Weevil, Rhynchophorus ferrugineus Olivier. Egyptian Journal of Biological Pest Control 19: 157-163

Tefera, T., and K. Pringle. 2003. Germination, radial growth, and sporulation of Beauveria bassiana and Metarhizium anisopliae isolates and their virulence to Chilo partellus (Lepidoptera: Pyralidae) at different temperatures. Biocontrol Science and Technology 13:699-704.

Vega, F.E., F. Posada, M.C. Aime, M. PavaRipoll, F. Infante, and S.A. Rehner. 2008 Entomopathogenic fungal endophytes. Biological Control 46:72-82.

Vidal, S., and L. Jaber. 2015. Entomopathogenic fungi as endophytes: plant-endophyteherbivore interactions and prospects for use in biological control. Current Science 109: 4654.

Wagner, B.L., and L.C. Lewis. 2000. Colonization of corn, Zea mays, by the entomopathogenic fungus Beauveria bassiana. Applied and Environmental Microbiology 66 (3):468-3473.

Wyrebek, M., C. Huber, K.R. Sasan, and J.M. Bidochka. 2011. Three sympatrically occurring species of Metarhizium show plant rhizosphere specificity. Microbiology 157:2904-2911. 